\title{
Observation Versus Inpatient Hospitalization: What Do Medicare Beneficiaries Pay?
}

\author{
Ann M. Sheehy, MD, MS ${ }^{1 *}$, Josh Boswell, JD², Bartho Caponi, MD³, Charles F. S. Locke, MD
}

\begin{abstract}
${ }^{1}$ Division of Hospital Medicine, Department of Medicine, University of Wisconsin School of Medicine and Public Health, Madison, Wisconsin; ${ }^{2}$ Department of Government Relations, Society of Hospital Medicine, Philadelphia, Pennsylvania; ${ }^{3}$ Division of Hospital Medicine, Department of Medicine, University of Wisconsin School of Medicine and Public Health, Madison, Wisconsin; ${ }^{4}$ Department of Utilization/Clinical Resource Management, Johns Hopkins Health System, and Department of Medicine, Johns Hopkins University School of Medicine, Baltimore, Maryland.
\end{abstract}

The problems surrounding hospital observation care and associated audits by Recovery Audit Contractors are gaining increased attention from both Congress and the Centers for Medicare \& Medicaid Services (CMS). ${ }^{1-5}$ On August 6, 2015, President Obama signed the NOTICE (Notice of Observation Treatment and Implication for Care Eligibility) Act (P.L. 114-42), ${ }^{4}$ which will require all Medicare beneficiaries receiving observation services for over 24 hours to be informed of their outpatient status. However, providers and hospitals are currently unable to answer a question that patients will certainly ask: What will an observation stay cost me compared to the same stay billed as an inpatient?

In this issue of the Journal of Hospital Medicine, Kangovi et al. $^{6}$ get a step closer to answering this question. Using 2010 to 2012 Medicare data, Kangovi and colleagues studied patient out-of-pocket costs per Medicare benefit period and found that the mean financial self-pay cost per beneficiary observation stay was less $(\$ 469.42)$ than the 2010 inpatient deductible $(\$ 1100){ }^{7}$ although about 1 in 10 observation stays exceeded the inpatient deductible. For beneficiaries with multiple observation stays per benefit period, the mean cumulative self-pay cost $(\$ 947.40)$ was also less than the inpatient deductible. However, for over a quarter of beneficiaries with multiple observation stays, the cumulative patient cost exceeded the inpatient deductible. The authors also found that black beneficiaries and those with more comorbidities were more likely to have multiple observation visits per benefit period, but higher out-of-pocket observation liability was associated with nonblack race, lower number of chronic conditions, and not being dual eligible.

Medicare beneficiaries hospitalized as inpatients are covered by Medicare Part A, with a single deductible

*Address for correspondence and reprint requests: Ann M. Sheehy, MD, Division of Hospital Medicine, Department of Medicine, University of Wisconsin School of Medicine and Public Health, 1685 Highland Avenue, MFCB 3126, Madison, WI 53705; Telephone: 608-262-2434;

Fax: 608-265-1420; E-mail: asr@medicine.wisc.edu

Additional Supporting Information may be found in the online version of this article.

Received: July 15, 2015; Accepted: July 17, 2015

2015 Society of Hospital Medicine DOI 10.1002/jhm.2440

Published online in Wiley Online Library (Wileyonlinelibrary.com). per benefit period, and are eligible for skilled nursing facility (SNF) coverage after 3 consecutive inpatient midnights. Medicare patients hospitalized as outpatients, including those receiving observation services, are not eligible for SNF coverage, must pay the cost of many self-administered pharmaceuticals, and are generally responsible for $20 \%$ of each service rendered, but with the per-service out-of-pocket $20 \%$ deductible capped at the equivalent to the current Part A deductible. However, there is no cumulative limit on the total out-of-pocket cost for outpatient observation (Part B) hospitalizations. ${ }^{8}$

Put in a slightly different way, "while [outpatient coverage] is designed to reflect the cost of caring for each individual beneficiary, [inpatient payment structure] is designed to reflect the cost of caring for an average beneficiary." 9 Because outpatient observation "payments are made per service, Medicare and beneficiary payment amounts both increase as the number of services provided increases," 9 which creates a threshold where the number and complexity of outpatient services exceeds the average inpatient stay, resulting in out-of-pocket observation costs exceeding the inpatient deductible. It makes sense that this threshold is more likely to be reached when the costs of multiple observation stays are added. Therefore, we should not be surprised at the findings of Kangovi et al., ${ }^{6}$ nor at those of the Office of Inspector General (OIG) ${ }^{9}$ using 2012 Medicare claims data, showing higher average out-of-pocket patient costs for short inpatient stays compared to observation stays, but with a significant minority of out-of-pocket observation patient stay costs exceeding the inpatient deductible.

Dr. Kangovi and colleagues should be applauded for their efforts to address this important Medicare beneficiary issue. Yet many questions remain. First, neither the OIG study nor Kangovi et al. fully included cost of self-administered medications in calculating patients' out-of-pocket patient liability. Second, Kangovi and colleagues did not account for beneficiary posthospitalization SNF costs, which would be substantially higher for any patients who did not have a qualifying 3-day inpatient stay, including all patients hospitalized "under observation." Third, both reports used data predating the 2midnight rule, so it is unlikely that beneficiary costs 
are comparable under current policy. Fewer long ( $>48$ hours) observation stays under the 2-midnight rule should reduce beneficiary financial burden, though this is unconfirmed. However, certain shorter, high-acuity, procedure-based observation stays could be more costly for patients. ${ }^{9}$ Fourth, Kangovi et al. also did not consider patients with both an inpatient stay and an observation stay in the same benefit period; these patients would be liable for both the inpatient deductible and the outpatient fees. Fifth, to be meaningful, comparison of beneficiary out-ofpocket liability for inpatient versus outpatient care must occur in the context of services rendered, similar to what was proposed by the House Ways and Means Subcommittee in their Hospital Improvements for Payment draft bill. ${ }^{10}$ Absent this, we should not conclude from this study that observation care is delivered at a "discounted" rate for patients when it is possible that lower out-of-pocket payments simply reflect, on average, fewer services rendered per observation stay when compared to an inpatient stay. Finally, the association between race, socioeconomic status, chronic conditions, and inpatient and observation stays merits further investigation. How such hospitalizations may relate to larger costs associated with lack of appropriate follow-up care, including costs for those who have adverse consequences when they curtail or forego SNF placement, must be considered.

Even if we accept these limitations and accede that out-of-pocket observation cost is, on average, less than inpatient, pitfalls of observation policy remain: a cap on out-of-pocket financial risk for hospital care and SNF coverage are protections only afforded to those Medicare beneficiaries hospitalized as inpatients. Although the aspect of CMS' 2-midnight rule that presumes inpatient status if a there is a physician's expectation of a medically necessary hospitalization of 2 or more midnights mitigates, but does not eliminate, the observation policy problem of uncapped out-of-pocket financial liability, it does not address the lack of SNF coverage following outpatient hospitalization. Further action and answers need to come from both Congress and CMS. At a recent Senate Special Committee on Aging hearing, Elizabeth Warren emphasized that CMS must accurately determine Medicare beneficiary out-of-pocket cost for observation care so providers can answer this question that patients undoubtedly ask. ${ }^{1}$ CMS should be called upon to make available estimates of beneficiary costs under the 2-midnight rule that include pharmacy charges, copayments (in the context of services rendered), and SNF costs. In addition, data should extend past beneficiary liability to detail differences in outpatient versus inpatient hospital reimbursement, systematic recovery auditing costs, and the total financial impact of maintaining 2 distinct (inpatient and outpatient) hospital reimbursement systems. ${ }^{11,12}$

Congress and CMS must ultimately go beyond cost estimates and actually reform the core problems in out- patient observation policy and the Recovery Audit program charged with enforcing status determinations. Congress should pass the Improving Access to Medicare Coverage Act of 2015 (H.R. 1571 and S. 843), which would guarantee SNF coverage for Medicare beneficiaries hospitalized for 3 consecutive midnights, regardless of whether those nights are inpatient or outpatient. ${ }^{13}$ Recovery Audit reform bills in the House (H.R. 2156) ${ }^{3}$ and under consideration in the Senate ${ }^{2}$ should be strongly supported. In addition, Congress and CMS should consider legislation or regulation that would cap outpatient hospitalization out-of-pocket liability at the inpatient Medicare beneficiary deductible. Alternatively, policymakers could finally recognize the current observation versus inpatient system for what it is: a payment structure with little clinical relevance. When the same exact medical care has 2 different hospital reimbursement rates and 2 different patient out-of-pocket financial liabilities, it may be time for policymakers to eliminate the false distinction altogether.

Disclosure: Nothing to report.

\section{References}

1. Senate Special Committee on Aging hearing: challenging the status quo: solutions to the hospital observation stay crisis. May 20, 2015. Available at: http://www.aging.senate.gov/hearings/challenging-thestatus-quo_solutions-to-the-hospital-observation-stay-crisis. Accessed July 1, 2015.

2. Senate Finance Committee Open Executive Session to consider an original bill entitled Audit \& Appeal Fairness, Integrity, and Reforms in Medicare Act of 2015. June 3, 2015. Available at: http://www. finance.senate.gov/hearings/hearing/? id=d84a2bef-5056-a032-522c8a3c9badb3ac. Accessed July 1, 2015.

3. Medicare Audit Improvement Act of 2015 (H.R. 2156). Available at: https://www.congress.gov/bill/114th-congress/house-bill/2156/text. Accessed July 1, 2015.

4. NOTICE Act (H.R. 876). Available at: https://www.congress.gov/bill/ 114th-congress/house-bill/876. Accessed July 1, 2015.

5. Centers for Medicare \& Medicaid Services Recovery Audit Program Improvements. Available at: http://www.cms.gov/Research-StatisticsData-and-Systems/Monitoring-Programs/Medicare-FFS-CompliancePrograms/Recovery-Audit-Program/Downloads/RAC-Program-Improve ments.pdf. Accessed August 13, 2015.

6. Kangovi S, Cafardi S, Smith R, Kulkarni R, Grande D. Patient responsibility for observation care. J Hosp Med. 2015;10(11):718-723.

7. Medicare general information, eligibility, and entitlement. Chapter 3-deductibles, coninsurance amounts, and payment limitations. Available at: http://www.cms.gov/Regulations-and-Guidance/Guidance/ Manuals/downloads/ge101c03.pdf. Accessed July 5, 2015.

8. What Medicare covers: find out if you're an inpatient or an outpatient-it affects what you pay. Available at: http://www.medicare.gov/ what-medicare-covers/part-a/inpatient-or-outpatient.html. Accessed July 10, 2015

9. Department of Health and Human Services. Office of Inspector General. Hospitals' use of observation stays and short inpatient stays for Medicare beneficiaries, OEI-02-12-00040. July 29, 2013. Available at: https://oig.hhs.gov/oei/reports/oei-02-12-00040.pdf. Accessed July $1,2015$.

10. Association of American Medical Colleges. Washington Highlights: Ways and Means Committee releases Medicare hospital bill. Available at: https://www.aamc.org/advocacy/washhigh/highlights2014/415486/ 112114waysandmeanscommitteereleasesmedicarehospitalbill.html. Accessed July 10, 2015.

11. Sheehy A, Graf B, Gangireddy S, et al. Hospitalized but not admitted: characteristics of patients with "observation status" at an academic medical center. JAMA Intern Med. 2013;173(21):1991-1998.

12. Sheehy A, Locke C, Engel J, et al. Recovery audit contractor audits and appeals at three academic medical centers. J Hosp Med. 2015; 10(4):212-219.

13. Improving Access to Medicare Coverage Act of 2015 (H.R. 1571/S. 843). Available at: https://www.congress.gov/bill/114th-congress/house-bill/ 1571. Accessed July 6, 2015. 